\title{
PERHITUNGAN BIAYA IRIGASI AIR TANAH MENGGUNAKAN MESIN GENERATOR SET DAN PEMBANGKIT LISTRIK TENAGA SURYA
}

\author{
Melda Fajra, ST, MT, Adrian Fadhli, S.Pd, MT, Zulpikal Adil
}

\begin{abstract}
ABSTRAK
Daerah Irigasi Air Tanah di Pakan Sinayan Kenagarian Kamang Mudia Kecamatan Kamang Magek Kabupaten Agam dengan luas $\pm 20,40$ ha merupakan sawah tadah hujan yang air irigasinya mengandalkan air hujan saja. Untuk mengatasi hal tersebut Balai Wilayah Sungai Sumatera V telah membangun sumur bor Irigasi Air Tanah yang terletak di Jorong Pakan Sinayan.

Studi ini bertujuan untuk mengetahui biaya modal dan biaya tahunan, kelayakan ekonomi dan waktu pengembalian modal investasi. Berdasarkan hasil perhitungan, besarnya biaya yang dikeluarkan untuk pembangunan Irigasi Air Tanah menggunakan Mesin Generator Set adalah sebesar Rp 2.886.443.895,00 dan biaya operasional \& pemeliharaan pertahun sebesar Rp 138.617.475,00. Biaya pengelolaan pertanian pertahun adalah Rp.453.430.800,00.Total penerimaan dari hasil sawah pertahun yang didapat petani adalah Rp. 983.178.000,00. Dari hasil perhitungan didapat nilai $\mathrm{BCR}=1,05, \mathrm{NPV}=\mathrm{RP} .473 .914 .568,00, \mathrm{IRR}=7,03 \%$, dan Break Event Point didapat pada tahun ke 8.Sehingga dapat disimpulkan bahwa proyek Pembangunan Longstorage Kali Mati ini layak secara ekonomi. besarnya biaya yang dikeluarkan untuk pembangunan Irigasi Air Tanah menggunakan Pembangkit Listrik Tenaga Surya adalah sebesar Rp 3.118.363.047,00 dan biaya operasional \& pemeliharaan pertahun sebesar Rp 46.850.600,00. Dari hasil perhitungan didapat nilai $\mathrm{BCR}=1,249$, NPV= RP. 2.291.028.516, IRR =10,36\%, dan Break Event Point didapat pada tahun ke 7. Sehingga dapat disimpulkan bahwa proyek Pembangunan Irigais air tanah ini layak secara ekonomi.
\end{abstract}

Kata kunci : Irigasi Air Tanah, BCR, NPV, IRR, Break Event Point

\begin{abstract}
Land Irrigation Area in Pakan Sinayan Kenagarian Kamang Mudia Kecamatan Kamang Magek Agam District with an area of \pm 20.40 ha is rain-fed rice field which irrigation water rely on rain water only. To overcome this, Sumatra River Basin V has built a groundwater water drill well located in Jorong Pakan Sinayan. The drill well is still using a diesel generator set generator sets as a generator.

This study aims to determine the cost of capital and annual costs, economic feasibility and payback period of investment capital. Based on the calculation, the amount of cost incurred for the development of ground water irrigation using Generator Set Machine is Rp 2,886,443,895.00 and the annual operational \& maintenance cost is $R p 138,617,475.00$. The cost of agricultural management per year is Rp.453.430.800,00.Total revenues from paddy fields per year obtained by farmers is $R p .983 .178 .000,00$. From the calculation results obtained value $B C R=1.05, N P V=$ $R P .473,914,568.00$, IRR $=7.03 \%$, and Break Event Point is obtained in the 8th year. So it can be concluded that the development project of Longstorage Kali Mati is economically feasible. the amount of cost incurred for the development of Irrigation of Ground Water using Solar Power Generation is $R p$ 3,118,363,047,00 and operational \& maintenance cost per year equal to $R p$ 46.850.600,00. From result of calculation got value of $B C R=1,249, N P V=R P .2 .291 .028 .516$, $I R R=10.36 \%$, and Break Event Point is obtained in year 7. So it can be concluded that the Irigais Development project is groundwater economically feasible if using one of the two generators, but the payback time is faster if using solar power plant.
\end{abstract}

Keywords: Irrigated Soil Water, BCR, NPV, IRR, Break Event Point
1. Pendahuluan
Dalam rangka menunjang ketahanan Latar Belakang pangan nasional, pemerintah berusaha untuk membangun atau meningkatkan berbagai 
fasilitas irigasi dengan berbagai sumber air irigasi. Salah satu sumber air irigasi yang belum optimal digunakan adalah pemanfaatan sumber air tanah dalam. Pengembangan irigasi air tanah dalam dapat menjadi pilihan yang menjanjikan apabila dilokasi tersebut ketersediaan sumber air permukaan sangat terbatas, sehingga secara teknis, sosial dan ekonomi tidak layak dilakukan.

Pada beberapa daerah di Provinsi Sumatera Barat telah dibangun beberapa titik Irigasi yang bersumber dari ar tanah dalam. Setelah beberapa tahun beroperasi, secara ekonomi Irigasi air tanah dalam dinilai cukup mahal dalam hal biaya operasi. Hal ini disebabkan karena irigasi air tanah dalam memerlukan mesin penggerak berupa generator set yang berbahan bakar Solar. Sehingga masyarakat pemakai air agak kewalahan dalam penyediaan bahan bakar yang harganya terus merangkak naik.

Seiring berkembangnya pemikiran manusia akan energi alternatif untuk memenuhi berbagai kebutuhan masyarakat, sehingga pemerintah melakukan terobosan dengan mengganti penggunaan mesin generator set dengan pembangkit listrik tenaga surya.

Penggunaan panel surya sebagai alternatif penganti generator set maupun listrik konvensional sebagai kebutuhan listrik untuk kebutuhan irigasi air tanah dalam, selain ramah lingkungan panel surya juga tidak membutuhkan perawatan yang mahal seperti layaknya penggunaan generator set, selain itu panel surya juga cocok untuk digunakan di wilayah Indonesia yang memiliki iklim tropis dan memiliki suhu panas yang cukup untuk penggunaan panel surya.

\section{Tujuan dan Manfaat}

Adapun tujuan penelitian ini adalah sebagai berikut :

a. Untuk Mengetahui besarnya biaya modal ( biaya langsung dan biaya tidak langsung) dan biaya tahunan untuk membangun dan mengoperasikan Jaringan Irigasi Air Tanah

b. Untuk mengetahui waktu pengembalian modal investasi (Break Event Point) pada masing-masing pembangkit pada Proyek Jaringan Irigasi Air Tanah.

Manfaat dari penelitian ini adalah Dari hasil penelitian ini diharapkan dapat mengetahui seberapa besar selisih biaya yang dibutuhkan untuk membangun dan mengoperasikan sistem jaringan irigasi air tanah dengan menggunakan mesin Generator Set Diesel dan tenaga matahari sebagai sumber listrik.

\section{Tinjauan Pustaka}

\section{Analisa Biaya}

Biaya investasi proyek dapat didefinisikan sebagai jumlah semua pengeluaran dana yang diperlukan untuk melakukan proyek sampai selesai mulai dari ide, studi kelayakan, perencanaan, pelaksanaan sampai pada operasi dan pemeliharaan membutuhkan bermacammacam biaya. Pada analisa kelayakan ekonomi, biaya-biaya tersebut dikelompokan menjadi beberapa komponen sehingga memudahkan analisa perhitungan semua biaya (Kodoatie, 1995:71):

\section{a. Biaya Modal}

- Biaya langsung, Biaya ini merupakan biaya yang diperlukan untuk pembangunan suatu proyek.

- Biaya tak langsung, Biasanya biaya untuk ini merupakan suatu angka prosentase dari biaya langsung, bisa, misal, 5\%, $10 \%$ ataupun 15\%. Hal ini sangat tergantung dari pihak pemilik dan perencana. Semakin berpengalaman pemilik ataupun perencana, besarnya prosentase ini lebih kecil.

\section{b. Biaya konstruksi}

Biaya konstruksi terdiri dari volume pekerjaan satuan, Harga satuan pekerjaan, dan Rencana Anggaran Biaya

\section{c. Biaya tahunan}

Biaya yang dikeluarkan selama pemanfaatan proyek sampai umur proyek selesai. biaya ini masih harus dipikul oleh pemilik/investor.

\section{Analisa Ekonomi}

Analisa ekonomi dalam studi pengembangan sumber daya air sudah merupakan hal rutin baik dalam tahap master plan, econnaissance, appraisal, feasibility study project completion report maupun dalam tahapan yang dianggap perlu dalam studi-studi khusus untuk mengevaluasi keberhasilan atau kegagalan suatu proyek pengembangan yang dibiayai oleh Bank atau lembaga keuangan lainnya. Bila dalam tahapan fesibility study proyek tersebut dianggap layak, maka dapat dilanjutkan dalam detail design dan pelaksanaan proyek 
(Suyanto, 2001:33).

Studi kelayakan adalah kajian permasalahan berupa laporan tertulis terhadap kelayakan suatu usulan atau perencanaan (Dalinastry, 2006:4).

a. Indikator kelayakan ekonomi

Untuk mendapatkan ukuran yang menyeluruh sebagai dasar penilaian kelayakan proyek, telah dikembangkan berbagai cara yang dinamakan kriteria investasi. Kriteria-kriteria yang umum dipakai dan dianjurkan untuk digunakan dalam evaluasi proyek adalah:

\section{- Benefit cost ratio (BCR)}

Perbandingan antara nilai sekarang (present value) dari manfaat (benefit) dengan nilai sekarang dari biaya (cost). Secara umum rumus untuk perhitungan BCR ini adalah (Pujawan, $1995: 259)$ :

$$
\mathrm{BCR}=\frac{\text { PVdarimanfaat }}{\text { PVdaribiaya }}
$$

Dimana :

$\mathrm{PV}=$ present value

$\mathrm{BCR}=$ benefit cost ratio

Sebagai ukuran dari penilaian suatu kelayakan proyek dengan metode BCR ini adalah jika BCR > 1 maka proyek dikatakan layak dikerjakan dan sebaliknya jika nilai $\mathrm{BCR}<1$ proyek tersebut secara ekonomi tidak layak untuk dibangun.

\section{- $\quad$ Net present value (NPV)}

Selisih antara present value dari manfaat dari present value dari biaya. Dimana langkah

yang harus dilakukan untuk perhitungan itu tidak banyak berbeda dengan langkah untuk perhitungan IRR. Secara umum rumus untuk perhitungan nilai Present value ini adalah sebagai berikut (Kuiper, 1971:45) :

$\mathrm{P}=\frac{\mathrm{F}}{(1+\mathrm{i})^{\mathrm{n}}}$

Dimana :

$\mathrm{P}=$ nilai sekarang

$\mathrm{F}=$ nilai pada tahun ke-n

$\mathrm{i}=$ nilai suku bunga

Dalam evaluasi proyek, nilai NPV pada

suku bunga pinjaman yang berlaku harus

mempunyai harga $>0$. Jika NPV $=0$,

berarti proyek tersebut mengembalikan persis seperti nilai investasi. Jika NPV < 0 , proyek tersebut dari segi ekonomi tidak layak untuk dibangun.

\section{- Internal Rate of Return (IRR)}

Internal Rate of Return ( IRR) dis ebut juga laju pengembalian yang merupakan besarnya tingkat bunga yang menjadikan biaya pengeluaran dan pemasukan besarnya sama Perhitungan IRR dapat diketahui dengan rumus sebagai berikut(Kuiper,1971:16):

$$
\text { IRR }=I^{\prime}+\frac{\mathrm{NPV}}{\text { NPV'-NPV" }^{\prime \prime}}
$$

Dimana :

I' = Suku bunga yang memberikan nilai NPV Positif

I" = Suku bunga yang memberikan nilai NPV negatif

$\mathrm{NPV}=$ Selisih antara Present Value dari manfaat dan Present Value dari biaya

NPV' = NPV Positif

NPV" = NPV Negatif

\section{- Break Event Point (BEP)}

Break Even Point (BEP) Break Even Point adalah titik pulang pokok dimana total revenue $=$ total cost. Terjadinya titik pulang pokok tergantung pada lama arus penerimaan sebuah proyek dapat menutupi segala biaya operasi dan pemeliharaan beserta biaya modal lainnya. Selama perusahaan masih berada di bawah titik BEP, selama itu juga perusahaan masih menderita kerugian. Semakin lama sebuah perusahaan mencapai titik pulang pokok, semakin besar saldo rugi karena keuntungan yang diterima masih menutupi biaya yang dikeluarkan (Ibrahim, 2003). Dalam rangka memproduksi atau menghasilkan suatu produk, baik barang maupun jasa, perlu terlebih dahulu merencanakan berapa besar laba yang ingin diperoleh. Artinya dalam hal ini besar laba merupakan prioritas yang harus dicapai, di samping hal-hal yang lainnya. Agar perolehan laba mudah ditentukan salah satu caranya adalah harus mengetahui terlebih dahulu berapa nilai BEP nya (Kasmir, 2009). Sigit, (1990) menyatakan bahwa analisa BEP adalah suatu teknik untuk mengetahui kaitan antara volume produksi, volume penjualan, harga jual, biaya produksi, biaya lainnya yang variabel dan tetap, serta laba rugi. Riyanto (2013) menyatakan bahwa 
untuk mencari BEP dapat digunakan rumus sebagai berikut :

$\mathrm{BEP}=$

\section{Metodolog}

Biaya Tetap

Pendapatan-Biaya

Lokasi penehıran анакикаn paua uaeran lahan pertanian pemakai sumur pompa Jorong Pakan Sinayan Nagari kamang Mudiak Kecamatan Kamang Magek Kabupaten Agam.

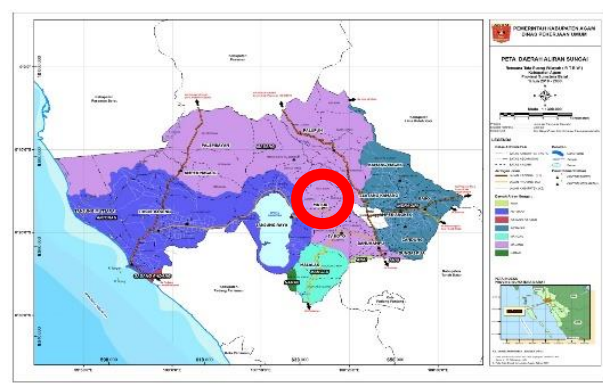

Gambar 1. Lokasi Studi

\section{Pengumpulan Data}

a. Jenis data yang digunakan dalam penelitian ini adalah:

1) Data kuantitatif yaitu data dalam bentuk angka seperti: luas daerah layanan, dan jumlah anggota P3A.

2) Data kualitatif yaitu data yang berupa pernyataan responden dan pertanyaan yang diberikan dalam bentuk kuisioner

b. Sumber data yang digunakan dalam penelitian ini adalah:

1) Data Primer

Data Primer adalah data yang diperoleh secara langsung dengan teknik Brain Storming, wawancara dan diskusi dengan pihak responden yang terlibat dalam pengelolaan jaringan irigasi. Selanjutnya diadakan penyebaran kuesioner dengan dipandu pada saat pengisiannya, sehingga diperoleh penilaian dari responden terhadap pengelolaan jaringan irigasi, pengoperasian sumur pompa untuk kebutuhan irigasi.

\section{2) Data Sekunder}

Data Sekunder diperoleh dari pihak lain atau dari laporan-laporan dan penelitian yang telah ada, dan yang ada relevansinya dengan masalah yang dibahas, data sumur bor yang ada di kecamatan Kamang Magek, jumlah P3A yang ada di kecamatan Kamang Magek, serta data dari beberapa instansi pemerintah terkait antara lain Kantor Balai Wilayah Sungai Sumatera V.

\section{Metode Pengolahan Data}

1) Studi Pustaka dan Literatur

Dalam penulisan penelitian ini dilakukan pengumpulan referensi yang diperoleh dengan membaca buku-buku literatur, jurnal, internet dan penelitian terdahulu yang berkaitan dengan penelitian yang sedang dilaksanakan.

2) Pengumpulan Data

Seluruh data yang dibutuhkan dalam penelitian dikumpulkan dengan cara studi lapangan untuk mendapatkan data primer, studi kepustakaan untuk mendapatkan data sekunder dan juga membuat asumsi yang diperlukan dalam penelitian.

3) Mengembangkan Asumsi

Asumsi-asumsi mengenai objek yang akan diteliti kemudian dikembangkan kembali untuk mempermudah dalam menghasilkan estimasi dan kesimpulan yang bermanfaat pada penelitian. Asumsi pada penelitian ini antara lain adalah sebagai berikut :

a. Sumber modal pembiayaan proyek pembangunan Irigasi Air Tanah di Jororng Pakan Sinayan Kecamatan Kamang Magek Kabupaten Agam yang diasumsikan $100 \%$ berasal dari dana APBN.

b.Tingkat suku bunga Bank Indonesia diasumsikan sebesar $7 \%$ per tahun.

c. Tingkat inflasi di Indonesia diasumsikan sebesar $10 \%$ dan $15 \%$. d.

e. Tingkat keuntungan atau rate of return diasumsikan sebesar 7\%.

f. Umur rencana bangunan PLTS adalah 25 tahun

4) Analis is Biaya

Analisis biaya yang dilakukan pada penelitian ini antara lain :

a. Menghitung rencana anggaran biaya perencanaan dan pembangunan kontruksi jaringan irigasi air tanah. 
b. Menghitung biaya Operasi dan Pemeliharaan dalam untuk pemanfaatan irigasi air tanah dalam.

c. Menghitung biaya pengelolaan lahan pertanian.

5) Analisis Aliran Kas (Cash Flow)

Setelah seluruh data dan asumsi yang dibutuhkan terkumpul, maka dilakukan input data untuk analisis dengan membuat aliran kas atau cash flow. Berdasarkan cash flow tersebut, data diolah menjadi informasi yang digunakan untuk menyelesaikan rumusan permasalahan dalam penelitian. Analisis data yang dilakukan pada penelitian ini antara lain adalah :

a. Menghitung Benefit Cost Ratio (BCR)

Hasil perhitungan BCR didapat dengan menggunakan rumus pada persamaan . Apabila nilai $\mathrm{BCR} \geq 1$, maka kegiatan investasi dapat dinyatakan layak untuk dilaksanakan. Namun jika tidak, maka kegiatan investasi dinyatakan tidak layak.

b. Menghitung Net Present Value (NPV)

Hasil perhitungan NPV didapat dengan menggunakan rumus pada persamaan 1. Apabila NPV bernilai positif, NPV $>0$, dan NPV memilikin nilai yang signifikan dari modal awal, maka kegiatan investasi dapat dinyatakan layak untuk dilaksanakan. Namun jika tidak, maka kegiatan investasi dinyatakan tidak layak.

c. Menghitung Internal Rate of Return (IRR)

Hasil perhitungan IRR didapat dengan menggunakan rumus pada persamaan 2. Apabila nilai IRR $\geq$ bunga pasar modal, maka kegiatan investasi dapat dinyatakan layak untuk dilaksanakan. Namun jika tidak, maka kegiatan investasi dinyatakan tidak layak.

3. Menghitung Break Even Point (BEP)

Break Event Point (BEP) didapatkan dari rumus pada persamaan Kemudian dari hasil perhitungan Payback Period (PP) akan dilakukan interpolasi untuk mendapatkan hasil BEP pada saat $\mathrm{NPV}=0$.

Garis besar tahap penelitian digambarkan dalam diagram alir pada gambar 1 dibawah ini :

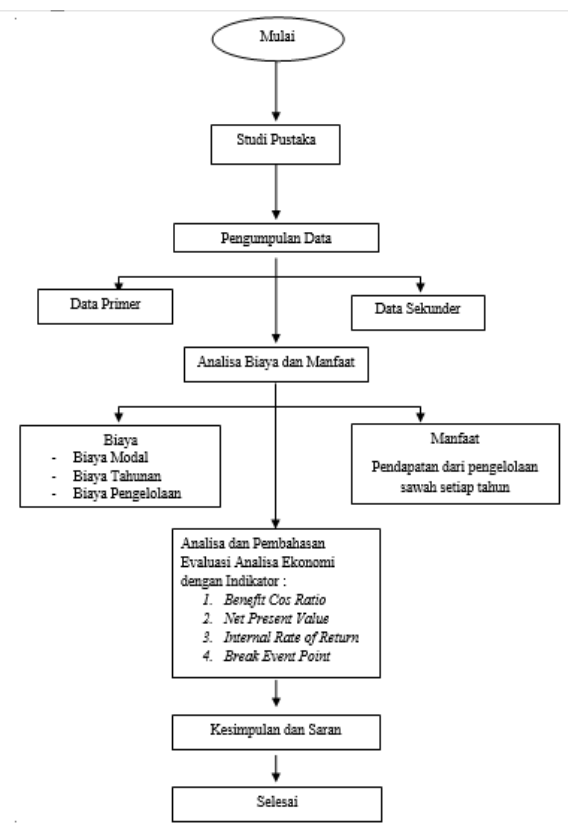

4. Hasil dan Pembahasan

Analis a Biaya

A. Menggunakan Generator Set

1) Biaya Modal

Biaya modal merupakan komponen penting dalam perhitungan kelayakan konomi. Yang termasuk biaya modal adalah :

- Biaya Langsung

Untuk proyek pembangunan Irigasi Air Tanah di Pakan Sinayan Kab. Agam biaya langsung yang diperlukan terdiri dari:

a. Biaya galian dan timbunan

b. Biaya pekerjaan persiapan

c. Biaya material

d. Biaya pekerja (upah tenaga kerja, sewa peralatan, dan lainnya)

Semua inilah yang nantinya menjadi menjadi biaya konstruksi yang ditawarkan pada kontraktor. Biaya konstruksi untuk Irigasi Air Tanah Menggunakan Mesin Generator Set sebesar Rp. 2,142,929,200.00

- Biaya Tak Langsung (Indirect Cost)

Biaya ini terdiri dari dua komponen,

yaitu:

a. Kemungkinan/hal yang tidak terduga (contengencies) dari 
biaya langsung.Biaya untuk ini merupakan suatu angka prosentase dari biaya langsung yaitu sebesar 5\%.

b. Biaya Teknik (engineering cost) Biaya teknik adalah biaya untuk pembuatan desain mulai dari studi awal (preliminary study), pra studi kelayakan, studi kelayakan, biaya perencanaan, dan biaya pengawasan selama waktu pelaksanaan konstruksi.

Biaya tidak langsung untuk proyek Pembangunan Irigasi Air Tanah menggunakan Mesin Generator Set di Pakan Sinayan adalah sebagai berikut:

Tabel 1. Biaya Tak langsung Pembangunan Irigasi Air Tanah menggunakan Mesin Generator Set

\begin{tabular}{|l|l|r|}
\hline No. & Uraian & \multicolumn{1}{l|}{ Jumlah } \\
\hline 1 & Administrasi & $48,702,936.65$ \\
\hline 2 & SID & $500,000,000.00$ \\
\hline 3 & $\begin{array}{c}\text { Biaya tak } \\
\text { terduga [ 5\%] }\end{array}$ & $194,811,746.60$ \\
\hline & Jumlah & $\mathbf{7 4 3 , 5 1 4 , 6 8 3 . 2 6}$ \\
\hline \multicolumn{2}{r|}{ Total } & $\mathbf{7 4 3 , 5 1 4 , 6 8 3 . 2 6}$ \\
\hline \multicolumn{2}{r}{ Dibulatkan } & $\mathbf{7 4 3 , 5 1 4 , 6 8 3 . 0 0}$ \\
\hline
\end{tabular}

Sumber : Hasil Perhitungan

Biaya modal untuk seluruh proyek Pembangunan Irigasi Air Tanah menggunakan Mesin Generator Set di Pakan Sinayan adalah sebagai berikut:

Tabel 2. Biaya modal Pembangunan Irigasi Air Tanah menggunakan Mesin Generator Set

\begin{tabular}{|r|r|r|}
\hline No. & \multicolumn{1}{|c|}{ Uraian } & \multicolumn{1}{c|}{ Jumlah } \\
\hline 1 & Biaya Langsung & $2,142,929,212.00$ \\
\hline 2 & $\begin{array}{l}\text { Biaya Tidak } \\
\text { Langsung }\end{array}$ & $743,514,683.00$ \\
\hline & Jumlah & $\mathbf{2 , 8 8 6 , 4 4 3 , 8 9 5 . 0 0}$ \\
\hline & Total & $\mathbf{2 , 8 8 6 , 4 4 3 , 8 9 5 . 0 0}$ \\
\hline & Dibulatkan & $\mathbf{2 , 8 8 6 , 4 4 3 , 8 9 5 . 0 0}$ \\
\hline
\end{tabular}

Sumber : Hasil Perhitungan

\section{a. Biaya Tahunan}

Biaya tahunan dari pompa irigasi air tanah meliputi perhitungan biaya operasi dan pemeliharaan. Perhitungan dan analisis biaya Operasi adalah sebagai berikut :
1) Biaya Operasi Tetap

Biaya operasi tetap merupakan biaya yang pasti dikeluarkan setiap mesin generator set beroperasi yang nilainya tetap. Besaran nilai biaya operasi tetap dapat dilihat pada tabel 3 berikut :

Tabel 3. Biaya Operasi tetap Irigasi Air Tanah menggunakan Mesin Generator Set

\begin{tabular}{|r|l|lr|}
\hline No. & \multicolumn{1}{|c|}{ Uraian } & \multicolumn{2}{|c|}{ Jumlah } \\
\hline 1 & Nilai Penyusutan Alat & Rp & $18.500 .000,00$ \\
\hline 2 & Biaya Pengembalian modal dan asuransi & Rp & $32.049,00$ \\
\hline 3 & Honor Operator [ Rp. 1200.000 x 12 Bln ] & Rp & $14.400 .000,00$ \\
\hline 4 & Biaya Pemeliharaan [ Rp. 200.000 x 20.40 ha] & Rp & $4.080 .000,00$ \\
\hline & Jumlah & Rp & $\mathbf{3 7 . 0 1 2 . 0 4 9 , 0 0}$ \\
\hline & Total & Rp & $\mathbf{3 7 . 0 1 2 . 0 4 9 , 0 0}$ \\
\hline & Dibulatkan & Rp & $\mathbf{3 7 . 0 1 2 . 0 0 0 , 0 0}$ \\
\hline
\end{tabular}

Sumber : Hasil Perhitungan

2) Biaya Operasi tidak tetap

Merupakan biaya yang dikeluarkan pada setiap pengoperasian mesin Generator Set yang besarannya selalu berubah tergantung jam pemekaian. Besaran nilai biaya operasi tetap dapat dilihat pada tabel 4 berikut :

Tabel 4. Biaya Operasi tidak tetap Irigasi Air Tanah menggunakan Mesin Generator Set

\begin{tabular}{|c|c|c|}
\hline No. & Uraian & Jumlah \\
\hline 1 & $\begin{array}{l}\text { Kebutuhan BBM [ } 6.5 \\
\text { Ltr/jam x Rp. 5.150 ] }\end{array}$ & $55,250.00$ \\
\hline 2 & $\begin{array}{l}\text { Oli Mesin [ } 10 \\
\text { Ltr/250 jamx Rp. } \\
33.000 \text { ] }\end{array}$ & $1,320.00$ \\
\hline 3 & $\begin{array}{l}\text { Gomok }[10 \mathrm{Kg} / 250 \\
\text { jam x Rp. } 22.000]\end{array}$ & 880.00 \\
\hline 4 & $\begin{array}{l}\text { Filter Oli [ } 1 \mathrm{Bh} \times 250 \\
\text { jam x Rp. } 120.000\end{array}$ & 480.00 \\
\hline 5 & $\begin{array}{l}\text { Filter Solar [ } 1 \mathrm{Bh} x \\
250 \text { jam x Rp. } 80.000\end{array}$ & 480.00 \\
\hline 6 & $\begin{array}{l}\text { Filter Udara }[1 \mathrm{Bh} \times \\
750 \text { jam x Rp. } 750.000\end{array}$ & $1,000.00$ \\
\hline & Jumlah & $59,410.00$ \\
\hline & Total & $59,410.00$ \\
\hline & Dibulatkan & $59,410.00$ \\
\hline
\end{tabular}

Sumber : Hasil Perhitungan

Berdasarkan analisa kebutuhan air irigasi untuk setiap waktu didapat jam operasi mesin generator set untuk satu kali musim tanam yaitu 735 jam. Sehingga didapat nilai biaya operasi tidak tetap yaitu

735 x Rp. 59.410,- = Rp.33.380.025,-

Dikarenakan untk satu tahun bisa tiga kali musim tanam maka:

Rp.33.380.025,- x 3 = Rp. 100.140.075,- 
Sehingga total biaya operasi untuk satu tahun adalah

Biaya tetap + Biaya tidak tetap

$=37.012 .000,-+100.140 .075,-=\mathbf{R p}$.

137.152.075,-

B. Menggunakan Tenaga Surya

1) Biaya Modal

Biaya Modal terdiri dari biaya langsung dan biaya tidak langsung. Biaya langsung proyek pembangunan Pompa Irigasi Air Tanah dapat ditampilkan sebagai berikut :

Tabel 5. Biaya langsung Pembangunan

Irigasi Air Tanah dengan tenaga surya

\begin{tabular}{|c|lr|c|}
\hline No. & \multicolumn{2}{|c|}{ Uraian } & \multicolumn{1}{c|}{ Jumlah } \\
\hline 1 & $\begin{array}{l}\text { Pekerjaan Rumah } \\
\text { Jaga Op }\end{array}$ & $376.707 .232,59$ \\
\hline 2 & $\begin{array}{l}\text { Pekerjaan Menara } \\
\text { Air }\end{array}$ & $131.475 .717,75$ \\
\hline 3 & $\begin{array}{l}\text { Pekerjaan Pagar } \\
\text { Pengaman Plts }\end{array}$ & $127.971 .757,37$ \\
\hline 4 & $\begin{array}{l}\text { Pekerjaan } \\
\text { Pengeboran }\end{array}$ & $503.661 .950,12$ \\
\hline 5 & $\begin{array}{l}\text { Pekerjaan Pompa } \\
\text { Dan Plts }\end{array}$ & $346.350 .000,00$ \\
\hline 6 & $\begin{array}{l}\text { Pekerjaan Jaringan } \\
\text { Pemipaan Dan } \\
\text { Asesories }\end{array}$ & Jumlah & $\mathbf{2 . 1 3 7 . 4 3 9 . 2 2 3 , 4 1}$ \\
\hline & PPN 10\% & $\mathbf{2 1 3 . 7 4 3 . 9 2 2 , 3 4}$ \\
\hline & Total & $\mathbf{2 . 3 5 1 . 1 8 3 . 1 4 5 , 7 6}$ \\
\hline & Dibulatkan & $\mathbf{2 . 3 5 1 . 1 8 3 . 1 4 5 , 0 0}$ \\
\hline
\end{tabular}

Sumber : hasil perhitungan

Biaya tidak langsung untuk pembangunan Irigasi Air Tanah di Pakan Sinayan adalah sebagai berikut :

Tabel 6. Biaya tidak langsung untuk pembangunan Irigasi Air Tanah dengan Mesin Generator Set

\begin{tabular}{|c|l|l|}
\hline No. & \multicolumn{1}{|c|}{ Uraian } & \multicolumn{1}{c|}{ Jumlah } \\
\hline 1 & Administrasi & $53.435 .980,59$ \\
\hline 2 & SID & $500.000 .000,00$ \\
\hline 3 & Biaya tak terduga & $213.743 .922,34$ \\
\hline Jumlah & $\mathbf{7 6 7 . 1 7 9 . 9 0 2 , 9 3}$ \\
\hline \multicolumn{2}{|l|}{ Total } & $\mathbf{7 6 7 . 1 7 9 . 9 0 2 , 9 3}$ \\
\hline
\end{tabular}

Sumber : hasil perhitungan

Jadi biaya modal untuk pembangunan satu titik Irigasi Air Tanah dengan menggunakan energi Pembangkit Listrik Tenaga Surya adalah sebagai berikut :

Tabel 7. Biaya modal Pembangunan Irigasi Air Tanah dengan Pembangkit Listrik Tenaga Surya

\begin{tabular}{|c|l|l|}
\hline No. & \multicolumn{1}{|c|}{ Uraian } & \multicolumn{1}{c|}{ Jumlah } \\
\hline 1 & Biaya Langsung & $2.351 .183 .145,00$ \\
\hline 2 & $\begin{array}{l}\text { Biaya Tidak } \\
\text { Langsung }\end{array}$ & $767.179 .902,00$ \\
\hline Jumlah & $\mathbf{3 . 1 1 8 . 3 6 3 . 0 4 7 , 0 0}$ \\
\hline Total & $\mathbf{3 . 1 1 8 . 3 6 3 . 0 4 7 , 0 0}$ \\
\hline Dibulatkan & $\mathbf{3 . 1 1 8 . 3 6 3 . 0 4 7 , 0 0}$ \\
\hline
\end{tabular}

2) Biaya Tahunan

Biaya tahunan dari pompa irigasi air tanah meliputi perhitungan biaya operasi dan pemeliharaan. Perhitungan dan analisis biaya adalah sebagai berikut :

a. Biaya Operasi

Biaya operasi terdiri dari biaya tetap dan biaya tidak tetap

1. Biaya Operasi tetap

Yang termasuk biaya tetap dalam pengoperasian Irigasi Air tanah dengan Pembangkit Listrik Tenaga Surya adalah:

Tabel 8. Biaya Tetap Operasi Irigasi Air Tanah

\begin{tabular}{|c|l|r|}
\hline No. & \multicolumn{1}{|c|}{ Uraian } & \multicolumn{1}{c|}{ Jumlah } \\
\hline 1 & Nilai Sisa Alat & $24.244 .500,00$ \\
\hline 2 & $\begin{array}{l}\text { Biaya Pengembalian } \\
\text { modal dan asuransi }\end{array}$ & $46.052,23$ \\
\hline 3 & $\begin{array}{l}\text { Honor Operator [ Rp. } \\
\text { 1200.000 x 12 Bln ] }\end{array}$ & $14.400 .000,00$ \\
\hline 4 & $\begin{array}{l}\text { Biaya Pemeliharaan [ Rp. } \\
\text { 200.000 x 20.40 ha] }\end{array}$ & $8.160 .000,00$ \\
\hline & Jumlah & $\mathbf{4 6 . 8 5 0 . 5 5 2 , 2 3}$ \\
\hline & Total & $\mathbf{4 6 . 8 5 0 . 5 5 2 , 2 3}$ \\
\hline & Dibulatkan & $\mathbf{4 6 . 8 5 0 . 6 0 0 , 0 0}$ \\
\hline
\end{tabular}

Sumber : Hasil perhitungan

C. Analisis Produksi Pertanian

1). Biaya modal pertanian padi

Tabel 9. Analisa biaya pengelolaan tanaman padi

\begin{tabular}{|c|l|r|}
\hline No. & \multicolumn{1}{|c|}{ Uraian } & Jumlah (Rp) \\
\hline A. & Modal & 240.000 \\
\hline 1 & Benih, 30 kg @ Rp. 8.000 & 1.000 .000 \\
\hline 2 & $\begin{array}{l}\text { Pupuk kandang 1000 kg } \\
\text { @ Rp. 1.000 }\end{array}$ & 195.000 \\
\hline 3 & $\begin{array}{l}\text { Pupuk Urea, 150 kg @ } \\
\text { Rp. 1.300 }\end{array}$ & \multicolumn{2}{|l}{} \\
\hline
\end{tabular}




\begin{tabular}{|c|c|c|}
\hline 4 & $\begin{array}{l}\text { Pupuk SP36, } 100 \text { kg@ } \\
\text { Rp.2.200 }\end{array}$ & 220.000 \\
\hline 5 & $\begin{array}{l}\text { Pupuk NPK Ponska } 300 \\
\text { kg @ Rp. } 2.300\end{array}$ & 690.000 \\
\hline 6 & $\begin{array}{l}\text { Petroganik, 1000kg@ } \\
\text { Rp.500 }\end{array}$ & 500.000 \\
\hline \multirow[t]{2}{*}{7} & $\begin{array}{l}\text { Pestisida / Insektisida, } 2 \\
\text { liter@ @p.75.000 }\end{array}$ & 150.000 \\
\hline & Jumlah Modal (A) & 2.995 .000 \\
\hline B. & $\begin{array}{l}\text { Biaya Operasional / } \\
\text { Upah Kerja }\end{array}$ & \\
\hline 1 & $\begin{array}{l}\text { Pengolahan lahan } 30 \\
\text { HOKp @ } 80.000 \text { atau } \\
\text { borongan }\end{array}$ & 2.400 .000 \\
\hline 2 & $\begin{array}{l}\text { Pencabutan bibit }+ \\
\text { penanaman } 20 \mathrm{HOKw} @ \\
\text { Rp. } 17.500\end{array}$ & 350.000 \\
\hline 3 & $\begin{array}{l}\text { Penyiangan + pemupukan } \\
\text { ke-1 16 HOKp @ Rp. } \\
30.000\end{array}$ & 480.000 \\
\hline 4 & $\begin{array}{l}\text { Penyiangan + pemupukan } \\
\text { ke-2 16 HOKp@ @p. } \\
80.000\end{array}$ & 1.280 .000 \\
\hline 5 & $\begin{array}{l}\text { Penyemprotan } 4 \mathrm{HOKp} \\
\text { @ Rp. } 80.000\end{array}$ & 320.000 \\
\hline 6 & $\begin{array}{l}\text { Panen dan pasca panen } 12 \\
\text { HOKp @ Rp. } 80.000\end{array}$ & 960.000 \\
\hline \multirow[t]{3}{*}{7} & $\begin{array}{l}\text { Biaya pengeringan } 8 \\
\text { HOKp @ Rp. } 80.000\end{array}$ & 640.000 \\
\hline & $\begin{array}{r}\text { Jumlah Biaya } \\
\text { Operasional (B) }\end{array}$ & 4.414.000 \\
\hline & Pengeluaran $(\mathbf{A}+\mathbf{B})$ & 7.409.000 \\
\hline
\end{tabular}

Sumber : Data pertanian

Biaya yang harus dikeluarkan untuk $1 \mathrm{Ha}$ sawah yaitu Rp. 7.409.000

Luasa Areal $=20.40 \quad$ x Rp.7.409.000 = Rp. $151,143,600$

Karena dalam 1 tahun bisa untuk tiga kali musim tanam

Rp. $151,143,600$ x $3=\mathbf{R p . 4 5 3 , 4 3 0 , 8 0 0}$

\section{Pendapatan}

Hasil panen sekitar yang didapat 5.6 ton gabah per hektar. Setelah dikeringkan hasilnya susut $18 \%$ menjadi 4.59 ton gabah kering per hektar. Dikarenakan pada titik sumur pompa pakan sinayan melayani 20.40 hektar sawah maka:

$20.40 \mathrm{Ha} \times 4.59$ Ton $=93.64$ Ton $=$ $93.640 \mathrm{Kg}$

Harga satu kg Gabah kering adalah Rp. 3.500,-

Maka hasil yang diperoleh

=93.640 kg x Rp.3.500,- = Rp. 327.726.000,-

Untuk satu tahun bisa 3 kali musim tanam maka pendapatan yang didapat : Rp. 327.726.000,- x $3=$ Rp. 983,178,000

\section{E. Analisis Ekonomi}

\section{a. Mesin Genset}

\section{1) Benefit Cost Ratio}

Dalam perhitungan perbandingan manfaat dan biaya (Benefit Cost Rati) ini masing masing manfaat memiliki nilai seragam. Hal ini dilakukan untuk memudahkan perhitungan. Tingkat suku bunga yang dipakai dalam perhitungan ini adalah $7 \%$. Dan usia guna sampai tahun 2032.

a. Komponen Biaya

$\begin{array}{lll}\text { Total Biaya Konstruksi } & = & 2.886 .443 .895 \\ \text { Faktor Konversi (F/P.7,1) } & = & 1,0700 \\ \text { Nilai biaya konstruksi } & = & 3.088 .494 .968 \\ \text { Total biaya O\&P } & = & 138.617 .475,00 \\ \text { Faktor Konversi (P/A,7,15) } & = & 9,108 \\ \text { Nilai Biaya OP } & = & 1.262 .527 .962,30 \\ \text { Total biaya pengolahan } & =453.430 .800 \\ \text { Faktor Konversi (P/A,7,15) } & =9,108 \\ \text { Nilai Biaya pengolahan } & =4.129 .847 .726,40 \\ \text { Total Biaya sekarang } & =8.480 .870 .656,350\end{array}$

b. Komponen Manfaat

$\begin{array}{llr}\text { Total Manfaat Irigasi } & = & 983.178 .000 \\ \text { Faktor Konversi (P/A,7,15) } & = & 9,108 \\ \text { Nilai Sekarang Manfaat } & = & 8.954 .785 .224\end{array}$

$$
\begin{aligned}
& \text { Sehingga BCR }=\frac{\text { Nilai Pendapatan }}{\text { Nilai Biaya }} \\
& =\quad \begin{array}{ll}
\text { Rp. } \quad 8.954 .785 .224 \\
\hline \text { Rp. } \quad 8.480 .870 .656
\end{array}
\end{aligned}
$$$$
=1,055
$$

Karena Benefit Cost Ratio $\geq 1$, maka proyek ini layak untukdilaksanakan.

\section{2) Net Present Value}

Metode kedua adalah analisa ekonomi dengan menggunakan selisih manfaat (benefit) dan biaya (cost).Dalam evaluasi ini nilai pada B-C pada tingkat suku bunga yang berlaku harus mempunyai harga $>0$. Jika nilai $\mathrm{B}-\mathrm{C}=0$ maka proyek tersebut mempunyai manfaat yang senilai dengan biaya investasinya. Jika B-C $<0$ maka proyek tersebut dari segi ekonomi tidak layak dibangun.

Perhitungan B-C untuk tingkat suku bunga 7 $\%$ adalah sebagai berikut :

$\begin{array}{llll}\text { Nilai sekarang biaya } & = & \text { Rp. } & 8.480 .870 .656 \\ \text { Nilai sekarang } & = & \text { Rp. } & 8.954 .785 .224\end{array}$


manfaat

NPV

$$
=\quad \text { Rp. } 473.914 .568
$$

Perhitungan NPV selengkapnya untuk berbagai suku bunga dapat dilihat dari tabel berikut :

Tabel 10 . NPV berbagai suku bunga

\begin{tabular}{|c|c|c|c|}
\hline \multirow{2}{*}{$\begin{array}{c}\text { Suku } \\
\text { Bunga }\end{array}$} & PV Benefit & PV Cost & \multirow{2}{*}{ B-C } \\
\cline { 2 - 3 } & $\mathrm{Rp}$ & $\mathrm{Rp}$ & \\
\hline $7 \%$ & 8.954 .785 .224 & 8.480 .870 .656 & 73.914 .568 \\
\hline $8 \%$ & 8.415 .020 .502 & 8.184 .700 .592 & 230.319 .910 \\
\hline $9 \%$ & 7.925 .397 .858 & 7.918 .724 .990 & 6.672 .868 \\
\hline $10 \%$ & 7.478 .051 .868 & 7.678 .207 .464 & - \\
\hline $12 \%$ & 6.696 .425 .358 & 7.265 .257 .963 & 568.832 .605 \\
\hline $15 \%$ & 5.748 .641 .766 & 6.781 .116 .743 & - \\
\hline
\end{tabular}

Sumber : Hasil perhitungan

\section{3) Internal Rate of Return}

Internal Rate of Return ( tingkat pengembalian internal ) didefinisikan sebagai tingkat suku bunga yang membuat manfaat dan biaya mempunyai nilai yang sama atau $\mathrm{B}-\mathrm{C}=0$ atau tingkat suku bunga yang membuat $\mathrm{B} / \mathrm{C}=1$ ( Kodoatie, 1995:112). Contoh perhitungan tingkat pengembalian internal untuk royek ini adalah sebagai berikut :

$$
\begin{aligned}
& \text { IRR = I' + ( I'- I') } \\
& \text { IRR = } 7 \%+\frac{6.672 .868}{\begin{array}{c}
(6.672 .868- \\
200.155 .596)
\end{array}} \times(10 \%-9 \%) \\
& \text { IRR }=7 \%+\frac{6.672 .868}{206.828 .464} \times 1
\end{aligned}
$$

$$
=7,0323
$$

Dari perhitungan tingkat pengembalian internal di atas dapat disimpulkan bahwa proyek Irigasi Air Tanah di Pakan Sinayan ini ini layak secara ekonomi. Hal ini disebabkan karena nilai IRR lebih besar dari nilai yang dipakai dalam evaluasi kajian ini yaitu sebes ar $7 \%$.

\section{4) Break Event Point}

Titik impas digunakan untuk menentukanlamanya waktu umtuk pengembalian modal. Pada suku bunga 7\%, titik impas investasi terjadi pada tahun ke 8 . Ini menandakan bahwa setelah tahun ke 8 keuntungan tahunan dari air baku dapat mengembalikan modal. Untuk perhitungan titik impas investasi setelah dicobacoba $\mathrm{B} / \mathrm{C}$
$=1$ dan kemudian diinterpolasi dari tabel bunga majemuk secara lengkap selanjutnya akan dilihat dari perhitungan dibawah ini:

$\begin{aligned} \mathrm{BEP} & =\frac{\text { Biaya Modal }}{\begin{array}{l}\text { Penghasilan }- \text { Biaya OP }- \\ \text { Biaya Pengolahan }\end{array}} \\ \mathrm{BEP} & =\frac{2.886 .443 .895,0000}{391.129 .725,00} \\ & =7,4 \text { tahun }=8 \text { tahun }\end{aligned}$

Dalam perhitungan didapat BEP < usia guna proyek, yaitu $\mathrm{BEP}=8$ tahun dengan usia guna 15 tahun. Sehingga Irigasi Air Tanah di Pakan Sinayan layak secara ekonomis.

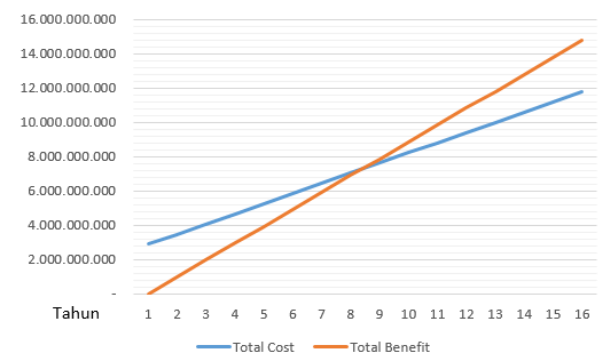

Gambar 1. Grafik BEP dengan Generator Set

\section{b) Pembangkit Listrik Tenaga Surya}

1) Benefit Cost Ratio

Dalam perhitungan perbandingan manfaat dan biaya (Benefit Cost Rati) ini masing masing manfaat memiliki nilai seragam. Hal ini dilakukan untuk memudahkan perhitungan. Tingkat suku bunga yang dipakai dalam perhitungan ini adalah $7 \%$. Dan usia guna sampai 25 tahun.

Komponen Biaya

Total Biay a Konstruksi $\quad=\quad 3.118 .363 .047$

Faktor Konversi (F/P.7,1) $=1,070$

Nilai biay a konstruksi $=3.336 .648 .460$

Total biaya O\&P $\quad=\quad 46.850 .600,00$

Faktor Konversi (P/A,7,25) $=11,654$

Nilai Biaya OP = $\quad=545.996 .892,40$

Total biay a pengolahan $\quad=\quad 453.430 .800,00$

Faktor Konversi (P/A,7,25) $=11,654$

Nilai Biay a pengolahan $\quad=\quad 5.284 .282 .543,20$

Total Biay a sekarang $\quad=\quad 9.166 .927 .895,89$ 
Komponen Manfaat

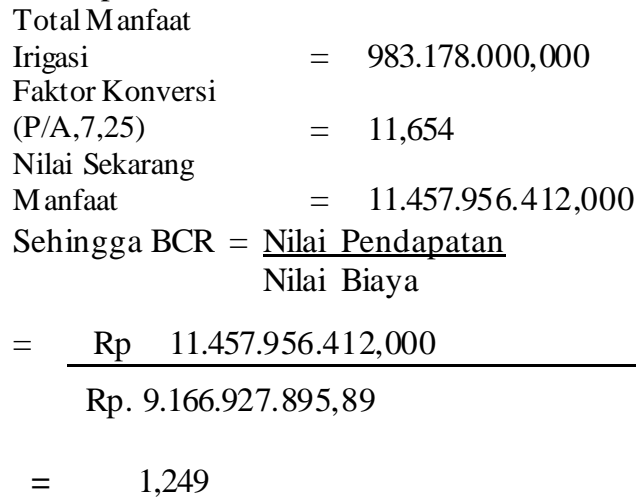

Karena Benefit Cost Ratio $\geq 1$, maka proyek ini layak untuk dilaksanakan

\section{2) Net Present Value}

Metode kedua adalah analisa ekonomi dengan menggunakan selisih manfaat (benefit) dan biaya (cost).Dalam evaluasi ini nilai pada B-C pada tingkat suku bunga yang berlaku harus mempunyai harga $>0$. Jika nilai $\mathrm{B}-\mathrm{C}=0$ maka proyek tersebut mempunyai manfaat yang senilai dengan biaya investasinya. Jika B-C $<0$ maka proyek tersebut dari segi ekonomi tidak layak dibangun.

Perhitungan B-C untuk tingkat suku bunga 7

$\%$ adalah sebagai berikut :

Nilai sekarang

$\begin{array}{lll}\text { manfaat } & =11.457 .956 .412 \\ \text { Nilai sekarang biaya } & =\frac{9.166 .927 .895}{\text { NPV }} \\ \text { Perhitungan } & =2.291 .028 .516\end{array}$

Perhitungan NPV selengkapnya untuk berbagai suku bunga dapat dilihat dari tabel berikut :

Tabel 11. NPV berbagai suku bunga

\begin{tabular}{|c|c|c|c|}
\hline \multirow{2}{*}{$\begin{array}{c}\text { Suku } \\
\text { Bung } \\
\text { a }\end{array}$} & PV Benefit & PV Cost & \multirow{2}{*}{$\mathrm{B}-\mathrm{C}$} \\
\hline & $\mathrm{Rp}$ & $\mathrm{Rp}$ & \\
\hline $7 \%$ & $\begin{array}{l}11.457 .956 .41 \\
2 \\
\end{array}$ & $\begin{array}{l}9.166 .927 .89 \\
6 \\
\end{array}$ & 2.291 .028 .516 \\
\hline $8 \%$ & $\begin{array}{l}10.495 .425 .15 \\
0\end{array}$ & $\begin{array}{l}8.708 .336 .03 \\
6\end{array}$ & 1.787 .089 .114 \\
\hline $10 \%$ & 8.924 .306 .706 & $\begin{array}{l}7.971 .253 .62 \\
0\end{array}$ & 953.053 .087 \\
\hline $15 \%$ & 6.355.262.592 & $\begin{array}{l}6.819 .936 .47 \\
4\end{array}$ & -464.673 .882 \\
\hline $18 \%$ & 5.375.034.126 & $\begin{array}{l}6.383 .523 .17 \\
9\end{array}$ & -1.008 .489 .053 \\
\hline $20 \%$ & 4.864 .764 .744 & $\begin{array}{l}6.217 .428 .02 \\
4\end{array}$ & -1.352 .663 .280 \\
\hline
\end{tabular}

Sumber : Hasil perhitungan

3) Internal Rate of Return
Internal Rate of Return ( tingkat pengembalian internal ) didefinisikan sebagai tingkat suku bunga yang membuat manfaat dan biaya mempunyai nilai yang sama atau $\mathrm{B}-\mathrm{C}=0$ atau tingkat suku bunga yang membuat $\mathrm{B} / \mathrm{C}=1$ ( Kodoatie, 1995:112). Contoh perhitungan tingkat pengembalian internal untuk royek ini adalah sebagai berikut :

$$
I R R=I^{\prime}+\frac{N P V '}{\text { NPV'-NPV' }}\left(I^{\prime \prime}-I^{\prime}\right)
$$

Dari perhitungan tingkat pengembalian internal di atas dapat disimpulkan bahwa proyek Irigasi Air Tanah di Pakan Sinayan ini ini layak secara ekonomi. Hal ini disebabkan karena nilai IRR lebih besar dari nilai yang dipakai dalam evaluasi kajian ini yaitu sebesar $7 \%$.

$$
\begin{aligned}
\operatorname{IRR} & =7 \%+\frac{953.053 .087}{\frac{9}{953.053 .087}}(15 \% \cdot 10 \%) \\
\operatorname{IRR} & =7 \%+\frac{953.053 .882}{1.417 .726 .968} \\
& \\
& =10,36
\end{aligned}
$$

Dari perhitungan tingkat pengembalian internal di atas dapat disimpulkan bahwa proyek Irigasi Air Tanah di Pakan Sinayan ini ini layak secara ekonomi. Hal ini disebabkan karena nilai IRR lebih besar dari nilai yang dipakai dalam evaluasi kajian ini yaitu sebes ar $7 \%$.

$\begin{array}{lrr}\text { 4) } & \text { Break Event Point } & \\ \text { Titik } \quad \text { impas } & \text { digunakan } & \text { untuk } \\ \text { menentukanlamanya } & \text { waktu } & \text { umtuk }\end{array}$ pengembalian modal. Pada suku bunga $7 \%$, titik impas investasi terjadi pada tahun ke 7 . Ini menandakan bahwa setelah tahun ke 7 keuntungan tahunan dari irigasi Airtanah menggunakan Listrik tenaga surya dapat mengembalikan modal. Untuk perhitungan titik impas investasi setelah dicobacoba B/C $=1$ dan kemudian diinterpolasi dari tabel bunga majemuk secara lengkap selanjutnya akan disajikan sebagai berikut:

$\begin{aligned} \mathrm{BEP} & =\frac{\text { Biaya Modal }}{\text { Penghasilan - Biaya OP }-} \\ \text { Biaya Pengolahan } & \\ \mathrm{BEP} & =\frac{3.118 .363 .047,0000}{482.896 .600,00}\end{aligned}$




$$
=\quad 6,45762=7 \text { tahun }
$$

Dalam perhitungan didapat BEP < usia guna proyek, yaitu $\mathrm{BEP}=7$ tahun dengan usia guna 25 tahun. Sehingga Irigasi Air Tanah di Pakan Sinayan layak secara ekonomis.

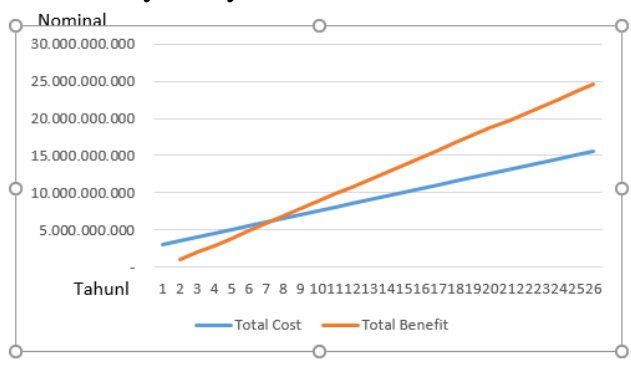

Gambar 6. Grafik BEP menggunakan Mesin Lis trik Tenaga Surya

Untuk lebih jelasnya perbandingan antara biaya modal pembangunan Irigasi Air tanah menggunakan mesin generator Set dan Tenaga Surya dapat dilihat dari tabel 4.15. berikut :

Tabel 12. Perbandingan biaya modal untuk pembangunan Irigasi Air Tanah Pakan Sinayan

\begin{tabular}{|c|c|c|c|c|c|}
\hline \multirow{2}{*}{ No } & $\begin{array}{c}\text { Jenis } \\
\text { Pembangkit }\end{array}$ & Biaya Modal & $\begin{array}{c}\text { Biaya } \\
\text { Operasi }\end{array}$ & $\begin{array}{c}\text { Biaya } \\
\text { Pengolahan }\end{array}$ & \begin{tabular}{c} 
Penghasilan \\
\cline { 3 - 6 }
\end{tabular} \\
\cline { 3 - 6 } 1 & $(\mathrm{Rp})$ & $(\mathrm{Rp})$ & $(\mathrm{Rp})$ & $(\mathrm{Rp})$ \\
\hline 1 & Generator Set & 2.886 .443 .895 & 138.617 .475 & 453.430 .800 & 983.178 .000 \\
\hline \multirow{2}{*}{2} & $\begin{array}{l}\text { Listrik Tenaga } \\
\text { Surya }\end{array}$ & 3.118 .363 .047 & 46.850 .600 & 453.430 .800 & 983.178 .000 \\
\hline
\end{tabular}

Sumber : hasil perhitungan

Sedangkan untuk perbandingan analisa Ekonomi untuk pembangunan Irigasi Air tanah menggunakan mesin generator Set dan Tenaga Surya dapat dilihat dari tabel 4.16. berikut :

Tabel.13. Perbandingan Analisa Ekonomi untuk pembangunan Irigasi Air Tanah Pakan Sinayan

\begin{tabular}{|r|l|c|c|c|r|}
\hline \multirow{2}{*}{ No } & \multirow{2}{*}{ Jenis Pembangkit } & \multicolumn{1}{c|}{ BCR } & NPV & \multicolumn{1}{c|}{ IRR } & \multicolumn{1}{c|}{ BEP } \\
\cline { 3 - 6 } & & $7 \%$ & $7 \%$ & $7 \%$ & Tahun \\
\hline 1 & Generator Set & 1,06 & 473.914 .568 & 7,03 & 7,38 \\
\hline & & 1,25 & 2.291 .028 .516 & 10,36 & 6,46 \\
\hline
\end{tabular}

Sumber : hasil perhitungan

\section{Kesimpulan dan Saran Kesimpulan}

Berdasarkan hasil analisa dan perhitungan yang telah dilakukan dalam kajian ini dapat disimpulkan sebagai berikut

1. Biaya modal pembangunan Irigasi Air Tanah dengan pembangkit mesin Generator Set yaitu sebesar Rp. 2.886.443.895,00 dan dengan Pembangkit Listrik Tenaga Surya adalah sebesar Rp. 3.118.363.047,00

2. Berdasarkan hasil perhitungan biaya total O\&P per tahun untuk Irigasi Air
Tanah menggunakan pembangkit Generator Set yaitu sebesar Rp. 138.617.475,00 dan dengan Pembangkit Listrik Tenaga Surya adalah sebesar Rp 46.850.600,00

3. Pendapatan petani dengan adanya Pembangunan Irigasi Air Tanah dengam pola tanam padi - padi - padi yaitu sebesar Rp. 983.178.000,-

4. Perhitungan dan analisa ekonomi Pembangunan Irigasi Air Tanah dengan pembangkit Mesin Genset yang meliputi BCR, NPV, IRR dan BEP dengan suku bunga $7 \%$ yaitu

- $\mathrm{BCR}=1,05>1$

- $\mathrm{NPV}=473.914 .568$

- $\operatorname{IRR}=7,03 \%$,

- Break Event Point = 7,4 tahun.

5. Perhitungan dan analisa ekonomi Pembangunan Irigasi Air Tanah dengan pembangkit Listrik Tenaga Surya meliputi BCR, NPV, IRR dan BEP untuk suku bunga $7 \%$

$$
\begin{aligned}
& \text { - } \mathrm{BCR}=1,249 \\
& \text { - } \mathrm{NPV}=\mathrm{Rp} .2 .291 .028 .516 \\
& \text { - } \quad \text { IRR }=10,36 \text {, } \\
& \text { - Break Event Point = 6,4 }
\end{aligned}
$$

6. Hasil analisa kelayakan ekonomi yang didapatkan berdasarkan perhitungan dengan tingkat suku bunga $7 \%$, dapat disimpulkan bahwa pembangunan Irigasi Air Tanah Pakan Sinayan secara ekonomi layak untuk dibangun.

Saran

Adapun saran dalam kajian ini adalah sebagaiberikut:

1. Hendaknya pihak terkait selalu meninjau dan turut serta dalam pemeliharaan sumur pompa agar dapat beroperasi secara optimal sesuai usia gunanya.

2. Dengan melihat besarnya potensi keuntungan yang ada di daerah irigasi ini, diharapkan dapat menjadi bahan pertimbangan pemerintah untuk bisa membangun lebih banyak sumur pompa yang menggunakan pembangkit listrik tenaga surya dikemudian hari

3. Setelah selesainya dibangun sistem penyediaan air baku ini nantinya pemerintah atau instansi terkait hendaknya memaksimalkan penanganan pemeliharaan, agar ketika terjadi 
kerusakan dapat segera diatasi dan meminimalisir biaya operasi dan pemeliharaan.

4. Mengajak partisipasi dari semua pihak untuk menjaga daerah resapan supaya tetap baik kondisinya sehingga kontinuitas debit air tanah relatif stabil meskipun di musim kemarau baik untuk masa sekarang maupun masa yang akan datang.

5. Sumur-sumur bor air tanah yang telah dikembangkan hendaknya dikelola dengan manajemen yang baik, sehingga tidak timbul konflik kepentingan dengan pengguna air yang lain.

\section{Daftar Pustaka}

Departemen Pekerjaan Umum. 1991 Pengembangan Air Tanah. Direktorat Jendral Pengairan.

Menteri Pekerjaan Umum dan Perumahan Rakyat. 2016. Analis is Harga Satuan Pekerjaan Bidang Pekerjaan Umum

Pabundu Tika, Mohammad. 1989. Pengelolaan Irigasi Sumur Pompa. Jakarta. Departemen Pekerjaan Umum

Robert, Kodoatie. 2005. Analisis Ekonomi Teknik. Yogyakarta ; ANDI

Syafinal. 2002. Pemanfaatan Air Tanah Untuk Irigasi Lahan Tadah Hujan (Tugas Akhir). Padang : Universitas Muhammadiyah Sumatera Barat.

Yasrimal. 2002. Pembuatan Sumur Bor Air Tanah Di Desa Sungai Talang Timur Kab. Lima Puluh Kota (Tugas Akhir). Padang : Universitas Muhammadiyah Sumatera Barat.

Dr. Ir. A. Hafied A. Gany, 1992. Rekayasa Sosial(Social Engineering) Dalam Pembangunan Pengairan. Jurnal Informasi Teknik. No. 9 halaman 5-15 Ir. FX. Marsudi Joyowiyono, 1983. Ekonomi Teknik - Jilid 1 dan 2. Badan Penerbit Departemen Pekerjaan Umum.

Kadariah, Lien Karlina dan Clive Gray, 1978. Pengantar Evaluasi Proyek. Program

Perencanaan Nasional, Lembaga Penyelidikan Ekonomi dan Masyarakat, Fakultas Ekonomi Universitas Indonesia, Publikasi PPN Serie 012, Jakarta.
Kota, Peta. 2017. Peta Kabupaten Kediri. http://petakota.blogspot.co.id/20 17/01/petakabupaten-kediri.html. (diakses 2 Februari 2017).

Kuiper, E, 1971. Water Resources Project Economics. Butterworths, London, England.

Linsley, Ray K. dan Joseph B. Franzini. 1996. Teknik Sumber Daya Air Jilid 2. Jakarta : Erlangga.

Muliakusuma, 2000. Proyeksi Penduduk. Jakarta : Lembaga Penerbit Fakultas Ekonomi Universitas Indonesia.

Newman, D.G., 1980. Engineering Economics Analisys. 2 nd ed., Engineering Press, San Jose, Ca.

Pujawan, I.N.P. 1995. Ekonomi Proyek. Jogjakarta : Liberty.

Pujawan, I.N.P. 2005. Ekonomi Teknik. Jakarta :

Suyanto, Adhi. 2001. Ekonomi Teknik Sumber Daya Air. Jakarta : Adhi Cipta Pres.

Wardana dkk. 2015. Pedoman Skripsi, Tesis dan Disertasi. Malang : Fakultas Teknik Universitas Brawijaya Malang. 